\title{
Understanding Sleep States
}

\author{
Dyck $\mathrm{N}^{1,2,3}$, Warren I4 $^{4}$ Tyebkhan J 1,2,3 \\ 1 Stollery Children's Hospital, Edmonton Alberta, Canada \\ 2 University of Alberta, Edmonton, Alberta, Canada \\ ${ }^{3}$ Edmonton NIDCAP Training Centre Canada (ENTCC), Edmonton, Alberta, Canada \\ ${ }^{4}$ University College London Hospital, London, UK
}

\section{Aims}

Understanding sleep states is critical in the interpretation of infant observations. Conversations with NIDCAP and APIB Professionals and Trainers revealed that sleep state recognition can continue to be challenging post-training.

Sleep is essential for healthy neurodevelopment and recent research on fetal and preterm sleep has expanded our understanding of sleep states, including the category of Indeterminate Sleep (INDS). ${ }^{1}$ The aim of this survey of NFI members was to explore areas of consistency and discrepancy in the clinical recognition of sleep states.

\section{Methods}

An online, anonymous survey was emailed to the NIDCAP Federation International (NFI) Membership. The survey asked respondents to identify clinical features of Quiet Sleep (QS), Active Sleep (AS) and Indeterminate Sleep (INDS). Respondents were asked to rank clinical signs in terms of the importance of each as a defining feature of that Sleep State (i.e. Is this clinical sign "Never / Occasionally / Usually / Always" seen, during this sleep state). Respondents were invited to add comments and to suggest references.

Responses were automatically collated by survey software (Google Forms). The response categories Never and Occasionally were combined manually, as were the categories Usually and Always. Given the questions asked and number of responses received, formal statistical analyses were not conducted.

\section{Results/Findings}

39 responses were received, (17 from NIDCAP Trainers and 17 from NIDCAP Professionals). Please see Table 1 for details. QS was recognized by almost all as "Regular breathing; No / Occasional eye opening / closing, eye movements or body movements". Six respondents added "Lower heart rate with minimal variability".

AS was recognized by most as "Irregular breathing; eye movements usually/always present, eye opening/closing occasionally present". Nine respondents added "facial movements and sucking". There was less consistency of response for Body Movements and Startles/Twitches.

INDS: 19/38, (including 5/17 NIDCAP Trainers) stated that they distinguish INDS, from QS and AS. INDS was recognized by most as "Irregular breathing". However, there was no consistency for Eyes Opening/Closing, Eye Movements, Body Movements or Startles/Twitches. Comments suggest that there is discrepancy about recognition of INDS. 19/38, (including 12/17 trainers) stated that they do not distinguish INDS, from QS and AS. Reasons included: not an option on NIDCAP observation sheet (12); not part of my training (7); not familiar with INDS.

In response to "At what gestational age (GA) does QS time equal AS time?", the median GA was $40 \mathrm{w}$, range $32 \mathrm{w}$ to 1 year of age $(n=28)$. Comments suggested that this GA may be dependent on GA at birth, and/or the caregiving environment.

Many other text responses highlighted points for deliberation, which we hope to present and discuss at the Annual NIDCAP Trainers Meeting 2020.

The most frequently recommended introductory reference was Graven and Browne $2008^{2}$ (8/23 responses). There was no consensus for more detailed, in-depth references. ${ }^{1,3}$

\section{Limitations}

The response rate was 39 of 242 (16\%) NFI members, and 17/45 Trainers (38\%), limiting generalizability of results.

This survey was not pre-piloted, and some respondents made us aware of ambiguities of wording, that might have led to differing interpretations of questions.

\section{TABLE 1. Results}

\begin{tabular}{|c|c|c|}
\hline QUIET SLEEP ( $\mathrm{n}=38$ ) & Never/Occasionally & Usually/Always \\
\hline Regular breathing & 3 & 35 \\
\hline Irregular breathing & 34 & 2 \\
\hline Eye movements & 34 & 3 \\
\hline Eyes opening/closing & 36 & 0 \\
\hline Body movements & 35 & 1 \\
\hline Startles/ Twitches / Tremors & 32 & 6 \\
\hline ACTIVE SLEEP ( $\mathrm{n}=38$ ) & Never/Occasionally & Usually/Always \\
\hline Regular breathing & 32 & 4 \\
\hline Irregular breathing & 6 & 32 \\
\hline Eye movements & 3 & 34 \\
\hline Eyes opening/closing & 26 & 12 \\
\hline Body movements & 14 & 24 \\
\hline Startles/ Twitches / Tremors & 20 & 18 \\
\hline $\begin{array}{l}\text { INDETERMINATE SLEEP } \\
(\mathrm{n}=20)\end{array}$ & Never/Occasionally & Usually/Always \\
\hline Regular breathing & 18 & 1 \\
\hline Irregular breathing & 5 & 15 \\
\hline Eye movements & 12 & 8 \\
\hline Eyes opening/closing & 12 & 8 \\
\hline Body movements & 11 & 9 \\
\hline Startles/ Twitches / Tremors & 12 & 8 \\
\hline
\end{tabular}




\section{Conclusion}

1. NIDCAP Trainers and Professionals are consistent in their clinical recognition of QS and AS.

2. Indeterminate Sleep (INDS) is not distinguished from QS and AS by many, possibly because they were not taught about INDS, and /or INDS is not an option on the NIDCAP Observation sheet. Considering the role that sleep plays in neurodevelopment we suggest that INDS be incorporated into Training Materials and into NIDCAP Observation.

3. There is little agreement about the age at which total QS equals total AS. Since this may be related to the infant's experience and has significance for neurodevelopment, this topic deserves further research.

References:

1. Dereymaeker A, Pillay K., et al. Review of sleep-EEG in preterm and term neonates, Early Human Development. 2017, 113:87-103. DOI:10.1016/j.earlhumdev.2017.07.003

2. Graven SN, Browne J. Sleep and Brain Development: The Critical Role of Sleep in Fetal and Early Neonatal Brain Development. Newborn and Infant Nursing Reviews. 2008, 8(4):173179. DOI:10.1053/j.nainr.2008.10.008

3. Bennet L, Walker DW, Horne RSC. Waking up too early - the consequences of preterm birth on sleep development. Journal of Physiology. 2018, 596(23):5687-5708. DOI: 10.1113/ JP274950

\section{1st Annual NIDCAP Trainers Meeting held virtually 21st - 23rd October 2020}

A few comments from the evaluation:

168 delegates attended from every NIDCAP Training Center
The virtual format was successful and very much appreciated
Shorter days

seemed as

productive

as full days

Moderators

were excellent
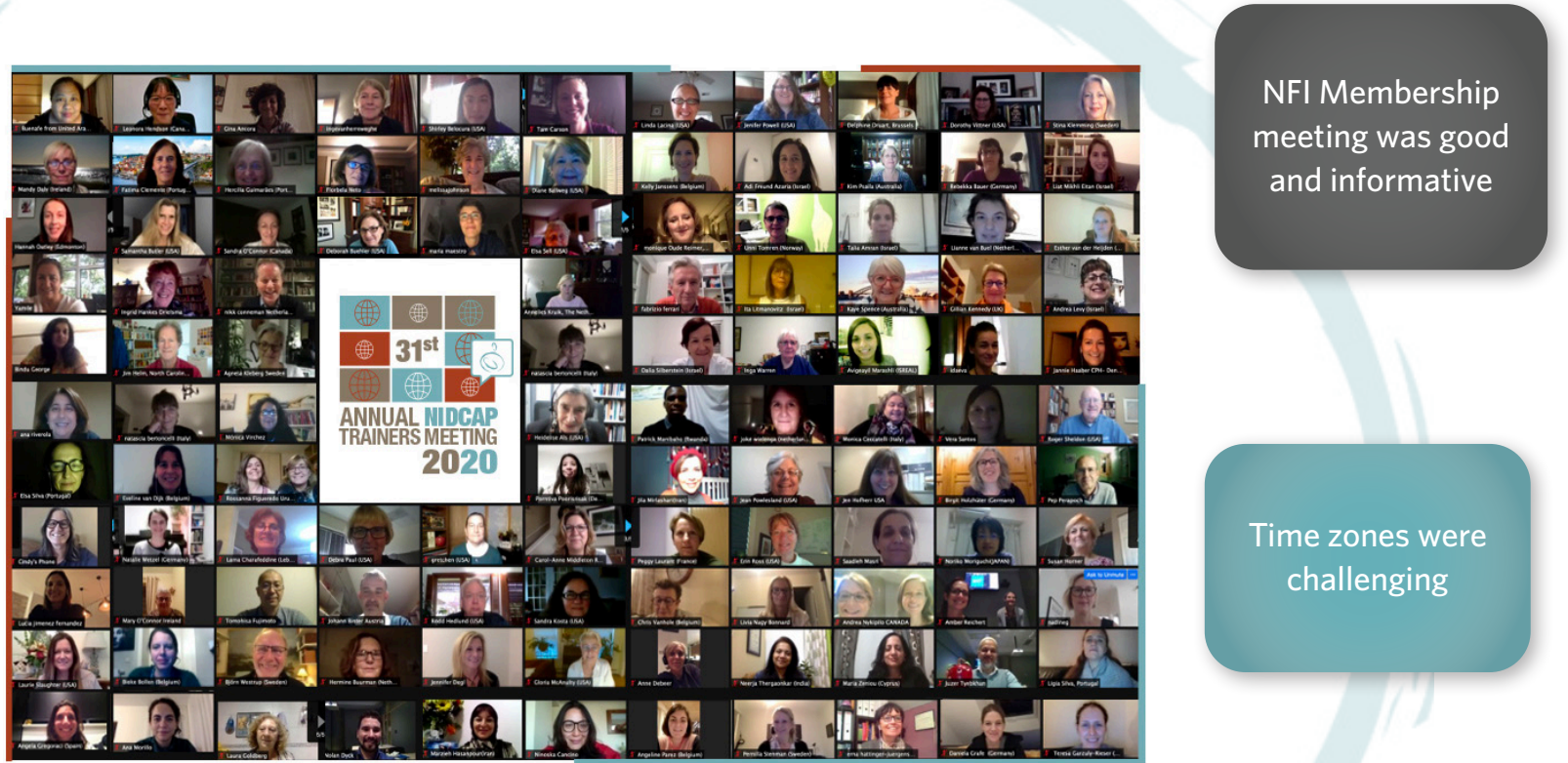

The prerecorded sessions worked well

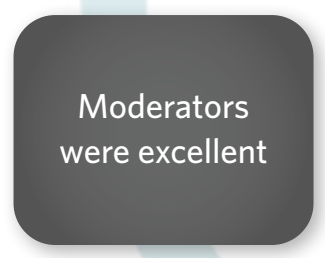

Pearls of Wisdom, personal story telling, abstracts and journal club
Explore opportunities to translate some presentations in advance 